\title{
Multisensory Learning Approach: Impacts on Phonological Awareness among Young ESL Learners in a Rural Setting
}

\author{
Muhammad Raihan Sapi'ee ${ }^{1}$, Kim Hua Tan ${ }^{2, *}$ \\ ${ }^{1}$ Faculty of Education, Universiti Kebangsaan Malaysia, 43600, Selangor, Malaysia \\ ${ }^{2}$ Faculty of Social Sciences and Humanities, Universiti Kebangsaan Malaysia, 43600, Selangor, Malaysia
}

Received August 30, 2020; Revised October 28, 2020; Accepted November 11, 2020

\section{Cite This Paper in the following Citation Styles}

(a): [1] Muhammad Raihan Sapi'ee, Kim Hua Tan, "Multisensory Learning Approach: Impacts on Phonological Awareness among Young ESL Learners in a Rural Setting," Universal Journal of Educational Research, Vol. 8, No. 12, pp. 6692 - 6705, 2020. DOI: 10.13189/ujer.2020.081234.

(b): Muhammad Raihan Sapi'ee, Kim Hua Tan (2020). Multisensory Learning Approach: Impacts on Phonological Awareness among Young ESL Learners in a Rural Setting. Universal Journal of Educational Research, 8(12), 6692 6705. DOI: 10.13189/ujer.2020.081234.

Copyright $(2020$ by authors, all rights reserved. Authors agree that this article remains permanently open access under the terms of the Creative Commons Attribution License 4.0 International License

\begin{abstract}
English is de facto global and primary lingua franca. English is proven to be a prolific communication tool and a language of choice used by speakers of diverse native languages across the globe to communicate. In Malaysia, English is taught and learned as a second language due to its importance and status in Malaysian society. However, the worrying state of English language literacy in rural settings, particularly in Malaysia, needs to be addressed to bridge the existing gap on language literacy between urban and rural dwellers, especially among young ESL learners. Reading impediment among young learners has been known to be due to a lack of knowledge in phonological awareness - syllable awareness, onset-rime awareness and phonemic awareness. This study employs a quasi-experimental study to investigate this phenomenon. It evaluates the effects of multisensory learning approach (P.A. Multiscape Application and low-technology modalities) on phonological awareness in a primary school in Maludam, Sarawak with 30 treatment and 30 comparison samples. Results revealed that students in the treatment group made significant gains in syllable awareness $(d=2.74)$, onset-rime awareness $(d=2.20)$, and phonemic awareness $(\mathrm{d}=2.56)$. Results suggested that the use of the multisensory learning approach was promising and effective in enhancing phonological awareness among young ESL children.
\end{abstract}

Keywords Multisensory Learning, Phonological
Awareness, Rural Setting, ESL

\section{Introduction}

In Malaysia, English is regarded as the second language and is used widely in government and social circles, implying that English is the second most important language after Bahasa Malaysia (Malaysia's national language in the hierarchy of Malaysian languages) $[21,41]$. English is taught as one of the core subjects in school, from preschool to secondary and tertiary education, with its curriculum designed to accommodate the needs of bilingual and multilingual societies in Malaysia [22]. In some parts of Malaysia, rural areas specifically, English is introduced as a foreign language $[2,29,36]$ due to the lack of exposure towards the language that the inhabitants have experienced. However, despite the important values that English holds in Malaysian society and the country herself, most children, especially of that in rural areas, have reflected failures in English acquisition, despite the long years of English language learning [7,20,29,36].

To improve English literacy proficiency in Malaysia, early interventions are highly encouraged as incentives to put forth efforts to enhance English language education in Malaysia. The worrying situations of English literacy in 
Malaysian rural areas have elicited much attentions and callings for early interventions in reading. Reading is known to be the core of academic success and one of the keys to reading success among young learners is the knowledge in phonological awareness (PA). PA has been known for decades to be one of the most crucial precursors of word reading in language learning and is able to predict later reading among young learners $[23,13]$. PA in Malaysia is still considered new and yet to be uncovered [43]. The present study aims to enhance PA among Year 1 children in a rural primary school in Sarawak, Malaysia, through both computerized and low-technology multisensory PA-based instructions.

\subsection{Literature Review}

\subsubsection{What is Phonological Awareness (PA)?}

PA is defined as a multilevel linguistic ability that is derived from a knowledge that oral language is comprised of smaller structures (syllables and phonemes), and is reflected through an explicit and conscious ability to dissect sounds into a distinctive unit and reassemble the sounds together to form a word [11,14,15,42] PA is said to develop long before children are explicitly aware of the sound system in the language they spoke through implicit judgment that allows them to acquire the mastery in speaking and listening in their mother tongue. PA has been receiving extensive attention from language teachers and therapists, but PA alone does not inspire reading success. PA can be measured and assessed through synthesis, manipulation, and analysis skills, which comprise blending, segmenting, identifying, manipulating, deleting, and substituting. PA in children is viewed to be developing in a hierarchical sequence instead of a linear pattern [27].

Children need to develop a sense of sensitivity of sound structure in oral language because it will highly affect their reading and writing abilities, and by extension, their academic successes. PA is recognized to be developing and evolving over time as children grow [6]. PA can and should be explicitly taught to children. In this perspective, general conception postulates that PA goes from larger to smaller sound units [26,17]. Furthermore, children are likely to develop their phonological sensitivity as they grow older in an independent manner that capacitates their language abilities to become stable $[17,23,25]$. A study by Bandini et al. [14] on 254 elementary school children aged between 5 to nearly 7 years old aimed to investigate the existing relationships between PA abilities and phonological working memory, presented that children aged 5 to 6 years old portrayed a good mastery of syllabic and onset-rime awareness. The opposite was recorded for awareness at the phonemic level. These results proved the hierarchical sequence of PA among children.

Druanovic et al. [25] studied 505 Bosnian preschool children aged 4 to 6 years old to identify the progression of PA among typically developing preschool children. They found that children progressed differently and consecutively in PA depending on the age variable. A battery of three PA matching tasks, comprising phonological discrimination, rhyme detection, initial phoneme, and one-letter knowledge tasks, were employed and administered on samples. These Bosnian children found to grow awareness of phonological discrimination and detection of initial phonemes before rhyme awareness. Rhyme awareness was found to be the most difficult task for children of all ages. A large number of children 5 to 6 years old recorded high scores for identification of initial phoneme. Thus, Bosnian children with transparent or regular orthography knowledge develop PA that begins with phonological discrimination, initial phoneme detection, and rhyme awareness. Druanovic et al. [25] verified that the results of PA progressions obtained from the samples were different, compared with those of English, possibly due to certain reasons such as saliency of orthographic patterns.

\subsubsection{Multisensory Learning}

Scott (1993) as cited in Rains et al. (2008), refers to multisensory as the process of learning new knowledge via the use of at least two or more integrated and crossed senses that may include visual, tactile-kinesthetic and audio. Some cases may involve the use of olfactory and taste senses. The use of multisensory learning is in line with the brief review of the existing learning theories, namely, Piaget's Cognitivism Theory, Bruner's Constructivism Theory, and Vygotsky's Scaffolding Theory [18]. According to Baines (2008) as cited in Korkmaz and Karatepe [37], the term multisensory is defined to be "methods that require students to activate their full faculties - seeing, hearing, smelling, tasting, moving, touching, thinking, intuiting, enjoying - in a variety of situations" (p. 81). Baines (ibid.) also mentioned that learning through the multisensory approach stimulates and involves many cognitive processes, starting from the communal relationship between sensory input and thinking, intense interaction with materials, and retaining the newly learned knowledge effectively for a long period.

Gorjian et al. [1] mentioned that visual techniques, which include artistic creation, helps pupils to comprehend abstract content, for instance, language, clearly and easily because they can associate the matter learned with their own experience. Auditory techniques mainly involve the use of sounds that are associated with verbal reasoning stimulations, and this technique adapts and uses multimedia dimensions and materials, such as songs. Tactile techniques include strategies that help in the increment of fine motor skills among pupils such as sand trays and clay modeling (ibid). Finally, kinesthetic techniques mainly adapt the movement of fine and gross motor skills, integrated in language learning (ibid). The multisensory learning approach has certain goals in teaching and learning. According to Mangal and Mangal 
(2014) as cited in Aja et al. [38], multisensory learning helps teachers to ensure the efficiency of the learning objectives by assisting teachers to plan and organize instructional strategies as systematically as possible. They also added that the multisensory learning approach aids pupils' learning by providing a self-exploratory element in the approach that involves active involvement in the instructional processes.

\subsubsection{Past Studies}

Multisensory-inspired learning interventions have been developed and practiced worldwide in the effort to increase PA among young language learners. Macaruso and Rodman [34] examined the effectiveness of Lexia Early Reading and Primary Reading programs on children's reading development in the US. Unification of audio-visual materials with tactile-kinesthetic activities is appropriate for the interventions to be classified as multisensory. That study indicated that the existing differences between the treatment and control groups were statistically significant, thereby suggesting that the intervention was successful in enhancing PA among young learners. In the UK, O'Callaghan et al. [35] determined the effectiveness of Lexia Reading Core5, finding that the programs were effective as a remedy for PA. However, they were less effective for segmenting skills.

Another study that used multisensory inspired learning intervention was by Wolgemuth et al. [19], which examined the effectiveness of ABRA in enhancing PA among children with indigenous backgrounds in Australia. ABRA was found to be effective in enhancing phonemegrapheme knowledge and PA among indigenous children. However, a contrasting result was obtained from Piquette et al. [32]. Data from this study showed that ABRA has no significant effect on phonological blending and word reading, significantly affecting letter-sound knowledge. However, effect size analysis provided a medium effect size of ABRA on phonological blending, showing that ABRA has a likely positive impression on PA. Echoed data was also obtained from Mak et al. [3], in which ABRA had a positive reverberation on PA-phonemic segmentation, particularly among ESL children in Hong Kong. Thus, ABRA is deemed to be effective to amplify and redress PA among ELL and ESL communities.

TrainerText is another multisensory-based intervention that can be adapted to enhance PA and decoding abilities among young learners. Messer and Nash [5] determined the extent of effectiveness of this intervention. Results of this study presented that TrainerText positively affected children's PA and possessed a significantly high effect size in PA development, compared with that of decoding skills. Gon and Yunus [8] examined the effects of the Interactive Digital Phonics Show (IDPS) on improving the PA of young ESL primary learners in a remote area in Malaysia. The syllable, rime, and phoneme knowledge of students were improved after receiving the IDPS treatment.
However, the native accents of children greatly affected their phonological processing and how they pronounced phonemes. These effects can be explored in other clinical linguistics studies.

Yeung et al. [39] evaluated the use of a language-enriched PA instruction program among young Hong Kong ESL learners. The program uses multisensory techniques, including kinesthetic, visual, and audio, and does not rely on printed materials. Various teaching and learning techniques are used in this intervention, such as body tapping to count syllables, oddity tasks through picture cards, and explicit PA instructions. However, language-enriched PA instruction only has slight effects on the reading and spelling of learners. Lee [24] investigated the effectiveness of using multisensory elements, adapted from the Orton-Gillingham (OG) approach, via two different modalities in improving the blending and segmentation skills of learners. Results show that these modalities had similar outcomes in the phonological tasks of learners. Nevertheless, both modalities provide ample inputs that can help enhance the PA of learners as long as the fundamental systems of multisensory learning are activated.

Another intervention that has been widely adopted as a remedial treatment to enhance PA was Jolly Phonics. According to Jamaluddin et al. [20], Jolly Phonics can effectively enhance the phoneme-segmentation ability of learners along with their phonographic and other PA skills, helping learners from rural areas develop their reading skills. Law and Hew [28] compared the results between computer-based Jolly Phonics and conventionally delivered contents of Jolly Phonics. They found that computer-based treatments, such as Computer Assisted Instructions, have statistically positive and significant effects on the alliteration, phoneme segmentation, and rhyming skills of young ESL learners, whereas blending skills have no significant effects. A retention test performed 10 weeks into the implementation of this intervention revealed that learners can emulate the same level of alliteration and rhyming skills. Anthony and Said [43] replicated these findings and found that Jolly Phonics can enhance the PA of primary ESL learners. Ahmad and Yunus [44] also found that this intervention improves the phoneme blending skills of learners. Therefore, Jolly Phonics can improve the PA of young English language learners.

\section{Methodology \& Materials}

\subsection{Research Questions}

This study aims to achieve several objectives, which are to compare and measure pupils' PA levels (syllable, onset-rime, and phonemic awareness) before and after the treatment procedure and to determine the effect of the 
intervention on pupils' PA. The research questions for this study are as follows.

1. Is there any significant differences between the control and the treatment groups?

2. Is there any significant differences in pupils' PA before and after the intervention's implementation?

\subsection{Research Design \& Sampling}

This particular study employed a quasi-experimental research design [12]. Two groups, namely, comparison and treatment, were carefully observed. In this study, the purposive sampling method was used. Purposive sampling, also referred to as judgment sampling, is defined as "the deliberate choice of a participant due to the qualities the participant possesses" [16, p.2]. Through this method of sampling, three classes of Primary 1 in a non-intense rural school in Sarawak, Malaysia were selected as the samples (treatment and control groups) for this research. A total of 60 pupils $(\mathrm{N}=60)$, were selected to be fully involved in the study. A total of 30 pupils were clustered into the comparison group, and the remaining 30 were clustered as the treatment group. These samples were carefully selected based on their age, internet accessibility and stability, and their reachability for a short-period physical meeting. All samples selected were typically developing children. Levels of English proficiency were collected for the researchers to cluster the samples accordingly to their levels of language aptitude. Samples chosen included low to average English language learners. Their levels of proficiency were determined by their performances in classroom-based assessment during orientation week in the first half of 2020 (TP 1-TP3). The demographic profiles of the samples are as follows.

Table 1. Demographic profiles of samples.

\begin{tabular}{|c|c|c|c|}
\hline \multirow{2}{*}{ Demographics } & \multicolumn{2}{|c|}{ Frequency, $N$} & \multirow{2}{*}{ Percentage $\%$} \\
\hline & Treatment Group & Comparison Group & \\
\hline \multicolumn{4}{|l|}{ Gender } \\
\hline Boy & 15 & 15 & 50.0 \\
\hline Girl & 15 & 15 & 50.0 \\
\hline Total & 30 & 30 & 100.0 \\
\hline \multicolumn{4}{|l|}{ Age } \\
\hline Seven years old & 30 & 30 & 100.0 \\
\hline Total & 30 & 30 & 100.0 \\
\hline \multicolumn{4}{|l|}{ Types of learners } \\
\hline Average students & 13 & 16 & 48.3 \\
\hline Low-achieving students & 17 & 14 & 51.7 \\
\hline Total & 30 & 30 & 100.0 \\
\hline \multicolumn{4}{|l|}{ Internet accessibility } \\
\hline Broadband & 15 & 17 & 53.3 \\
\hline Dial-up & 0 & 0 & 0 \\
\hline Mobile phone/Tablets & 15 & 13 & 46.7 \\
\hline None & 0 & 0 & 0 \\
\hline Total & 30 & 30 & 100.0 \\
\hline \multicolumn{4}{|l|}{ Learning devices during MRO } \\
\hline Computers/Mobile Phone & 30 & 30 & 100.0 \\
\hline Television & 0 & 0 & 0 \\
\hline Book & 0 & 0 & 0 \\
\hline None & 0 & 0 & 0 \\
\hline Total & 24 & 22 & 100.0 \\
\hline
\end{tabular}




\subsection{Procedure}

This particular study allocated multiple treatment sessions. The treatment group was given multisensory learning treatment, and the comparison group goes through normal teaching and learning experiences. This research was conducted in three months (partially done during the Movement Control Order period of COVID 19 Pandemic). Treatment sessions were conducted for approximately 30 45 minutes per day, three days a week. This research adapted a pre- and posttests design. Information and data were gathered, analyzed, and compared for both sessions.

Both experimental and comparison groups were subjected to the pre-test and post-test. This was done to ensure that the two groups involved were comparable, and to determine the effect of the intervention developed on children's PA. The inclusion of the comparison group in this study would allow the researcher to observe any significant changes in the outcomes subsequent to the treatment, or otherwise, effects contributed by other quintessential factors such as maturation. The pre-test was initiated one week prior to the treatment in order to circumvent or reduce any confounded effects of testing upon samples. As for the post-test, the scores were obtained two weeks upon the completion of the intervention.

\subsection{Instrumentation}

The Phonological Awareness Skills Test (PAST), a screening test adapted by Brenda Wright in 2005, is one of the well-established and formalized measures of PA. PAST is used to assess all skills enumerated under PA. Results from the tests might assist educators to emphasize the aspects of oral language that might not be thoroughly addressed in normal classroom instructions. Included with this test is a manual that contained all information regarding the test's administration. The test is appropriate for all levels of English language learners. The researcher possesses a bachelor's degree in Teaching of English as a Second Language (TESL), more than two years of teaching experience, and a considerable foundation analyzing sound structures in English with background knowledge in phonology. Thus, the researcher conducted the assessment using this test. To enhance reliability, individual testing procedures were consulted with the licensed school counselor. The test originated from the US, and the researcher intended to measure PA development among the samples via a formalized test of PA used on the international scale. As this test was adapted for the first time on samples in this setting, an alpha reliability test [9] was employed to measure the internal reliability of the test, and the value of .89 was obtained.

In PAST, syllable awareness, onset-rime awareness, and phonemic awareness were gauged through several tasks which could be described as follows: (i) syllable awareness: syllable blending, syllable segmentation, and syllable deletion; (ii) onset-rime awareness: rhyme recognition and onset-rime production; and (iii) phonemic awareness: phoneme isolation of initial sounds, phoneme isolation of final sounds, phoneme blending, phoneme segmentation, phoneme deletion of initial sounds, phoneme deletion of final sounds, phoneme deletion of the first sound in a blend and phoneme substitution of first and initial sounds. Data from this study was analyzed through SPSS Version 23.

\subsection{Interventions Specifications}

For this particular study, the researcher employed multisensory technology [10] and the conventional multisensory approach. The reason for this choice is the effects of prolonged school closure due to Covid-19 outbreaks, causing teachers to seek effective alternative methods of remote learning. In this study, samples clustered in the treatment group were divided into three major groups, namely, beginning, intermediate, and advanced learners. Treatments given to these samples were done accordingly to their levels, and a lesson could cover up to 45 minutes.

\subsubsection{P.A. Multiscape Application}

P.A. Multiscape is an educational learning application developed by the researchers. The application was developed based on the well-established and well-respected OG Approach, as well as SMARTER Phonics approach which has been widely utilized in the state of Sarawak. Installed with interactive multisensory technology elements, the said intervention intends to integrate an enchanting and fascinating adventure on students' reading journeys. The application includes several PA-based instructions, some built-in mini-games, and rewards for students as the impetus to learn and engage themselves in the learning process. The application includes audio-visual integration, voice-over, and word pronunciation features. This application is student-centered, and teacher's roles can be replaced with the dictation built in the app. However, considering the locality of this study, the teacher's guidance is highly necessary to explain and translate the instructions. This app is specially developed for preschool to 2 nd grade children in this setting.

\subsubsection{Conventional Multisensory Approach}

The conception of colored-grapheme synesthesia into real-life applications was adapted in this study. Every letter and sound taught was associated and accompanied by their individual colors and actions. For example, the letter "a" that produces the /æ/ sound is linked to the visual imagery of "ant". The action of chin patting, indicating the sound production of that specific phoneme, is limited to the area appointed to the face (place of articulation). The color associated with the letter " $\mathrm{a}$ " is red, representing the visual 
imagery of the phoneme, which is "ant." Other activities in the learning repertoire include finger, palm, and air spelling; writing letters using clay; connecting dots; phoneme, syllable, and word ensembles; shoulder-arm-hand movements; writing on canvas; arranging bottle caps of phonemes; action songs; and body tapping. These activities are all included in the conventional modality of the multisensory approach (refer to Figure 1).

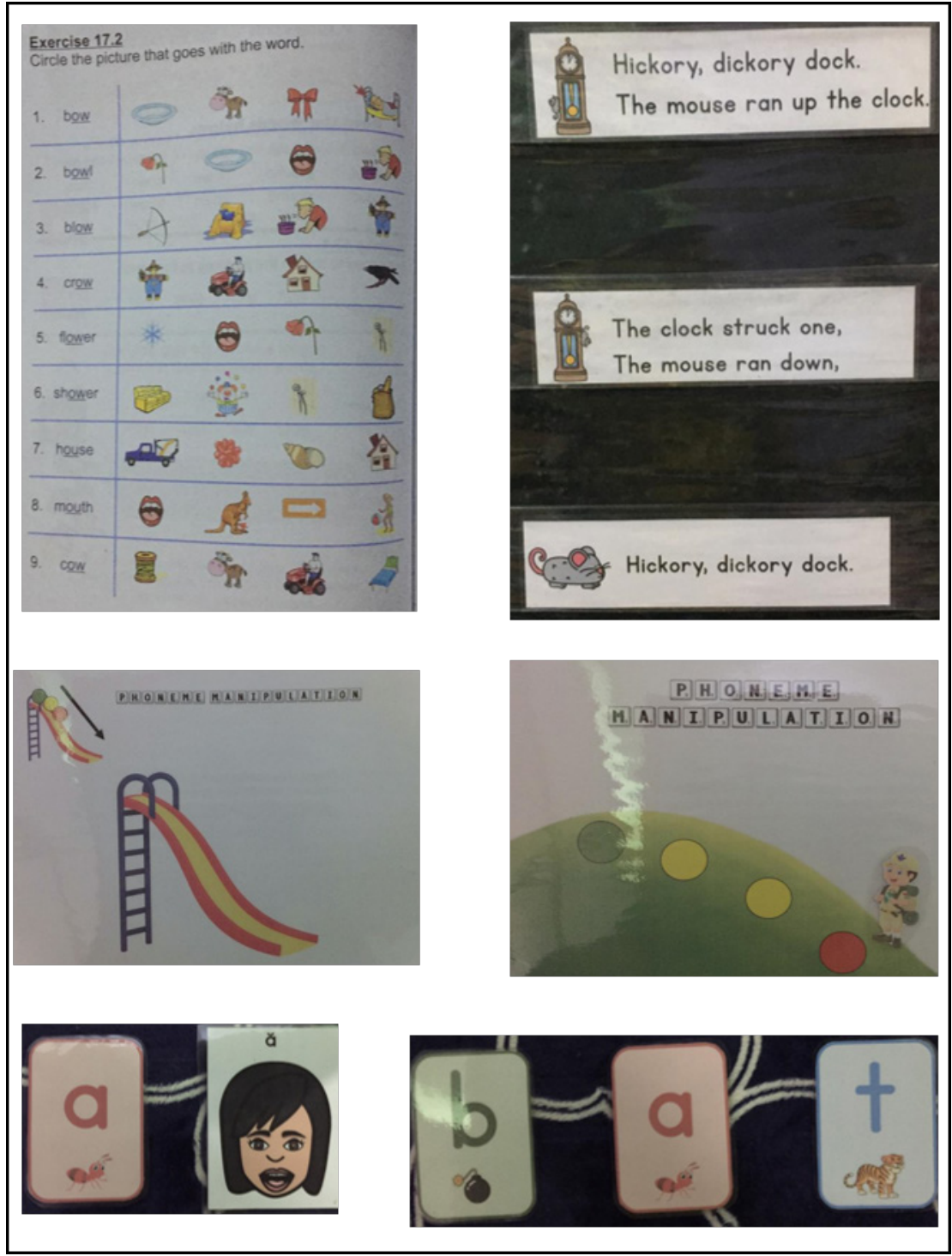

Figure 1. Samples of physical multisensory activities 

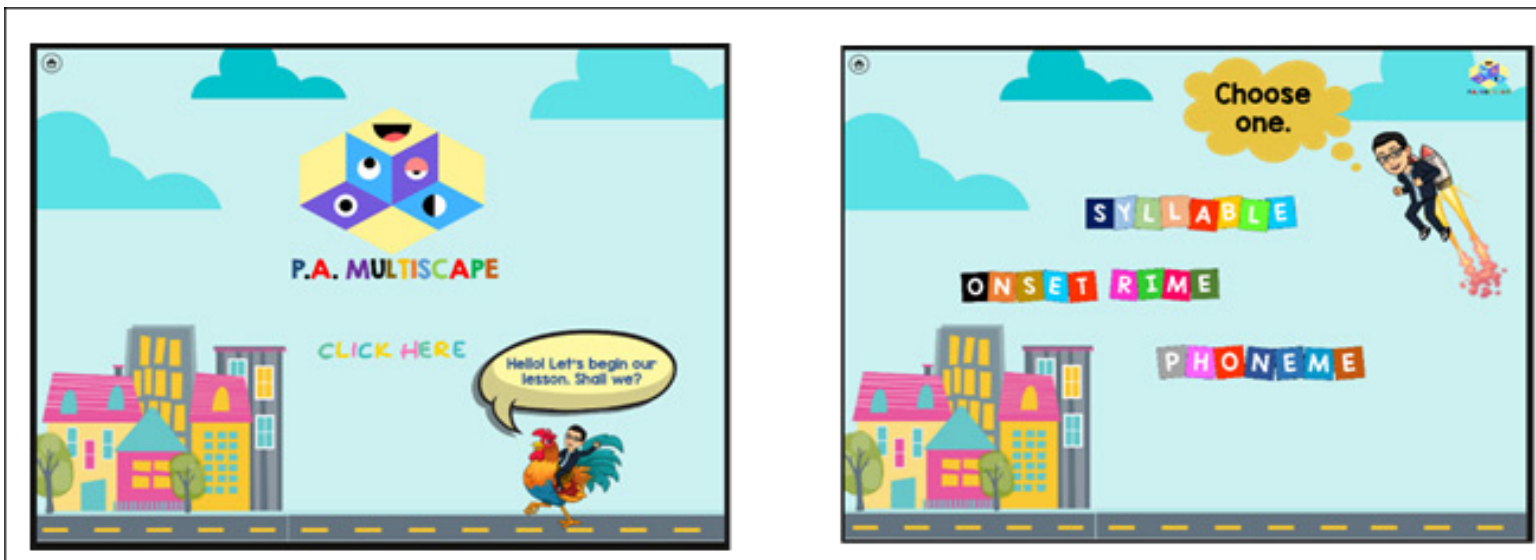

P.A. Multiscape is designed with colourful and interesting features to attract samples' attentions to learn.

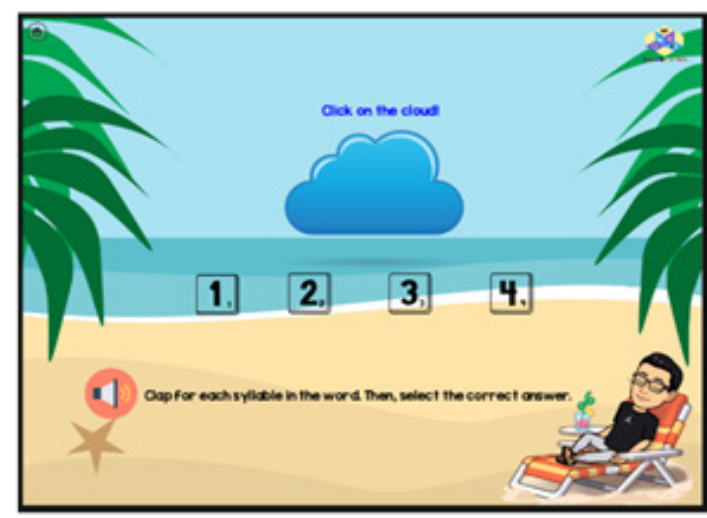

Example of syllable-awareness related activity (syllable clapping segmentation)

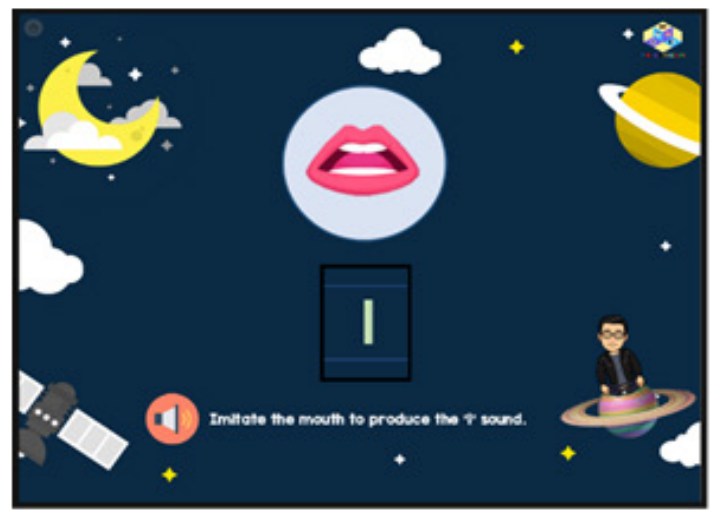

Samples were explicitly taught about place of articulation for the phoneme $/ /$.

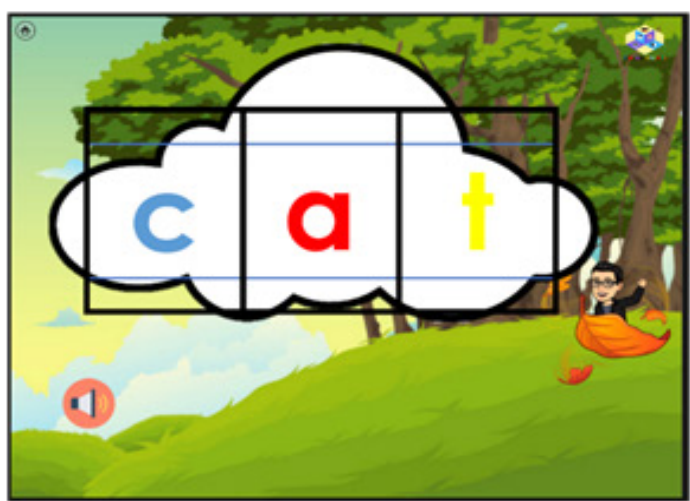

Samples were given chances to listen to the word and trace the words accordingly to the phonemes composed in the word.

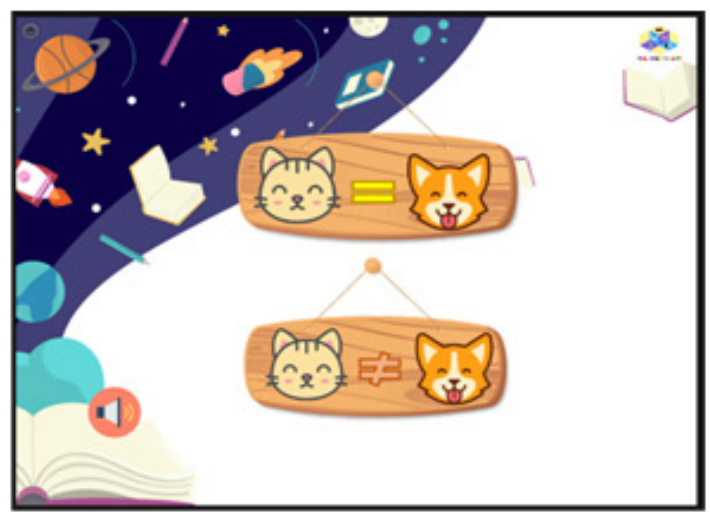

Rhyme detection activity. 


\section{Results}

\subsection{Research Question 1}

The data obtained from pre- and posttests from both treatment and comparison groups are shown in the following table 2 .

The comparison group had a mean score of 41.67 for syllable awareness during the pre-test period. An increment of 24.81 was obtained on syllable awareness for the posttest period $(\mathrm{M}=66.48)$. As for onset-rime awareness, the mean score for the comparison group on the pre-test was 41.67 and its counterpart was 50.00. An increment value of 8.33 was obtained for this specific skill in the comparison group. As for phonemic awareness, the comparison group was able to obtain a mean score of 34.93 for pre-test and 40.97 for the posttest. This finding resulted in an increment value of 6.04 for phonemic awareness in the comparison group. The standard deviation values from the comparison group ranged from 14.53 to 25.89 , indicating widespread data distribution.

By contrast, the treatment group was able to generate a high value of increment if the comparison was made based on pre and posttests. For syllable awareness, an increment value 43.89 was documented $(\mathrm{M}$ pretest $=$ 41.67, $\mathrm{M}$ posttest $=85.56$ ). As for onset-rime awareness, an increment value of 36.95 was obtained ( $\mathrm{M}$ pretest $=$ 40.83, $\mathrm{M}$ posttest $=77.78$ ). Finally, for phonemic awareness, an increment value of 36.11 was obtained (M pretest $=34.93, \mathrm{M}$ posttest $=71.04)$. The standard deviation values for all skills from the treatment group ranged from 12.45 to 20.80 , indicating widespread data distribution. Below is a bar chart comparing the mean scores obtained by both groups during pre and posttests.

Table 2. Tabulation of data obtained from treatment and comparison groups

\begin{tabular}{|c|c|c|c|c|c|c|c|c|}
\hline \multirow{4}{*}{ PA Skills } & \multicolumn{8}{|c|}{$N=60$} \\
\hline & \multicolumn{4}{|c|}{ Comparison Group $(\mathrm{n}=\mathbf{3 0})$} & \multicolumn{4}{|c|}{ Treatment Group $(n=30)$} \\
\hline & \multicolumn{2}{|c|}{ Pre-test } & \multicolumn{2}{|c|}{ Post-test } & \multicolumn{2}{|c|}{ Pre-test } & \multicolumn{2}{|c|}{ Post-test } \\
\hline & $\mathrm{M}(\%)$ & $\mathrm{SD}(\%)$ & $\mathrm{M}(\%)$ & $\mathrm{SD}(\%)$ & $\mathrm{M}(\%)$ & $\mathrm{SD}(\%)$ & $\mathrm{M}(\%)$ & $\mathrm{SD}(\%)$ \\
\hline Syllable Awareness & 41.67 & 14.93 & 66.48 & 22.77 & 41.67 & 20.10 & 85.56 & 10.78 \\
\hline Onset-Rime Awareness & 41.67 & 15.93 & 50.00 & 25.89 & 40.83 & 12.45 & 77.78 & 18.22 \\
\hline Phonemic Awareness & 34.93 & 14.53 & 40.97 & 23.25 & 39.31 & 14.53 & 71.04 & 20.80 \\
\hline Total PA Scores & 40.61 & 13.79 & 52.48 & 20.77 & 39.14 & 13.97 & 78.13 & 15.21 \\
\hline \multicolumn{9}{|l|}{90} \\
\hline \multicolumn{9}{|l|}{80} \\
\hline \multicolumn{9}{|l|}{70} \\
\hline \multicolumn{9}{|l|}{60} \\
\hline \multicolumn{9}{|l|}{50} \\
\hline \multicolumn{9}{|l|}{40} \\
\hline 30 & & & & & & & & \\
\hline 20 & & & & & & & & \\
\hline \multicolumn{9}{|l|}{10} \\
\hline \multicolumn{9}{|c|}{$\begin{array}{c}\text { Pre-Test (Treatment } \\
\text { Group) }\end{array}$} \\
\hline \multicolumn{3}{|c|}{ Syllable Awareness } & Onset-Rir & le Awar & \multicolumn{3}{|c|}{ Phonemic Awareness } & \\
\hline
\end{tabular}

Figure 3. Comparison of mean scores between pre- and posttests from treatment and comparison groups 
To determine the significant values of differences between comparison and treatment groups, a statistical test was used. The hypotheses intended to be examined are below.

$\mathrm{H}_{0}$ : There is no significant difference in PA between comparison and treatment groups.

$\mathrm{H}_{\mathrm{a}}$ : There is a significant difference in PA between comparison and treatment groups.

A normality test was run for all 60 samples $(\mathrm{N}=60)$, and the results from the Kolmogorov-Smirnov test indicated that all data were not normally distributed. Hence, a non-parametric test of Mann Whitney $\mathrm{U}$ was used, the results of which are as follows. (Table 3 )

Table 3 summarized the results of the Mann Whitney U test on treatment and comparison groups' performances in PA subskills for both pre- and posttests. During the pretest, the mean ranks of all PA skills in the treatment group were higher compared with that of the comparison group. The comparison group scored slightly lower in syllable awareness during the pretest $(\mathrm{Mdn}=38.89)$, compared with the treatment group $(\mathrm{Mdn}=41.67)$. However, the result from Mann Whitney $U$ proved that the difference was insignificant, at $U(30,30)=442.00, Z=-0.12$, and $p>$ 0.05 . The same situation was repeated for onset-rime awareness, in which both comparison and treatment groups obtained a similar median score $(\mathrm{Mdn}=41.67)$. On that note, the difference was insignificant, at $\mathrm{U}(30,30)$ $=449.50, Z=-0.01$, and $p>0.05$. For phonemic awareness, the comparison group had a higher performance score $(\mathrm{Mdn}=36.46)$ compared with the treatment group $(\mathrm{Mdn}=34.38)$. However, the difference was documented to be insignificant, at $\mathrm{U}(30,30)=366.00$, $\mathrm{Z}=-1.24$, and $\mathrm{p}>0.05$. This evidence suggested that the differences documented during the pretest were insignificant. Thus, the null hypothesis failed to be rejected for the pretest period.

By contrast, in the posttest, significant differences were detected for all subskills of PA. For syllable awareness, the treatment group scored a higher result $(\mathrm{Mdn}=86.11)$ compared with the comparison group ( $\mathrm{Mdn}=80.56)$. Thus, the treatment group's performance in syllable awareness was significantly higher than the comparison group, at $U(30,30)=210.50, Z=-3.62$, and $p<0.05$. A similar situation was observed for onset-rime awareness and phonemic awareness. For onset-rime awareness, the treatment group scored a higher median value $(\mathrm{Mdn}=$ 83.33) compared with the comparison group ( $\mathrm{Mdn}=$ 62.50). The difference in onset-rime awareness scores was recorded significant, at $\mathrm{U}(30,30)=146.00, \mathrm{Z}=-4.56$, at $\mathrm{p}<0.05$. As for phonemic awareness, the median score of the treatment group $(\mathrm{Mdn}=79.17)$ was higher compared with its counterpart $(\mathrm{Mdn}=41.67)$. Therefore, the observed contrasting value was significant, at $\mathrm{U}(30,30)=$ $150.00, Z=-4.44$, and $p<0.05$. This evidence supported that differences between the treatment group and comparison group were significant for the posttest. Thus, the null hypothesis was rejected in favor of the alternative hypothesis.

The differences observed between the comparison and treatment groups were significantly contrasted. Further analyses were made to compare and evaluate either the differences between the two groups on individual skills (refer to Table 4). Results from Mann Whitney U statistically proved that the differences for all skills were significant. For syllable blending, the treatment group obtained a higher score $(\mathrm{Mdn}=5.00)$ compared with the comparison group $(\mathrm{Mdn}=4.00)$, and the differences were identified to be significant, at $U=99.00, Z=-5.50$, and $p<$ 0.05 . A significant difference was also found in syllable segmentation, at $U=260.00, Z=-2.99$, and $p<0.05$, between the treatment $(\mathrm{Mdn}=5.00)$ and comparison groups $(\mathrm{Mdn}=3.00)$. For syllable deletion, similar data was observed, in which a significant difference was documented, at $\mathrm{U}=330.00, \mathrm{Z}=-2.07$, and $\mathrm{p}<0.05$, between the treatment $(\mathrm{Mdn}=3.00)$ and comparison groups $(\mathrm{Mdn}=$ $0.50)$.

Table 3. Results from Mann Whitney U test for the first research question

\begin{tabular}{|c|c|c|c|c|c|c|c|c|}
\hline Period & Skills & Groups & $\mathbf{N}$ & Median & Mean Rank & Mann-Whitney U & $\mathbf{Z}$ & Sig. \\
\hline \multirow{6}{*}{ Pre-Test } & \multirow{2}{*}{ Syllable Awareness } & Comparison & 30 & 38.89 & 30.23 & \multirow{2}{*}{442.00} & \multirow{2}{*}{-0.12} & \multirow{2}{*}{0.91} \\
\hline & & Treatment & 30 & 41.67 & 30.77 & & & \\
\hline & \multirow{2}{*}{ Onset-rime Awareness } & Comparison & 30 & 41.67 & 30.48 & \multirow{2}{*}{449.50} & \multirow{2}{*}{-0.01} & \multirow{2}{*}{0.99} \\
\hline & & Treatment & 30 & 41.67 & 30.52 & & & \\
\hline & \multirow{2}{*}{ Phonemic Awareness } & Comparison & 30 & 36.46 & 27.70 & \multirow{2}{*}{366.00} & \multirow{2}{*}{-1.24} & \multirow{2}{*}{0.21} \\
\hline & & Treatment & 30 & 34.38 & 20.50 & & & \\
\hline \multirow{6}{*}{ Post-Test } & \multirow{2}{*}{ Syllable Awareness } & Comparison & 30 & 80.56 & 22.52 & \multirow{2}{*}{210.50} & \multirow{2}{*}{-3.62} & \multirow{2}{*}{0.00} \\
\hline & & Treatment & 30 & 86.11 & 38.48 & & & \\
\hline & \multirow{2}{*}{ Onset-rime Awareness } & Comparison & 30 & 62.50 & 20.37 & \multirow{2}{*}{146.00} & \multirow{2}{*}{-4.56} & \multirow{2}{*}{0.00} \\
\hline & & Treatment & 30 & 83.33 & 40.63 & & & \\
\hline & \multirow{2}{*}{ Phonemic Awareness } & Comparison & 30 & 41.67 & 33.30 & \multirow{2}{*}{150.00} & \multirow{2}{*}{-4.44} & \multirow{2}{*}{0.00} \\
\hline & & Treatment & 30 & 79.17 & 40.50 & & & \\
\hline
\end{tabular}


Skills enumerated under onset-rime awareness were rhyme recognition and onset-rime production. Rhyme recognition documented that the treatment group obtained a higher score $(\mathrm{Mdn}=5.00)$ than did the comparison group $(\mathrm{Mdn}=4.00)$, which was proven to be significant, at $\mathrm{U}=182.00, \mathrm{Z}=-4.32$, and $\mathrm{p}<0.05$. As for onset-rime production, the treatment group recorded a higher score $(\mathrm{Mdn}=5.00)$ than did the comparison group $(\mathrm{Mdn}=3.00)$, with a significant value of $U=186.50, Z=-4.07$, and $p<$ 0.05 .

Eight phonemic awareness tasks were assigned for samples to complete. All differences identified between the two related groups were found to be significant. For phoneme isolation of initial sounds, a significant difference in performance was found between treatment $(\mathrm{Mdn}=5.00)$ and comparison groups $(\mathrm{Mdn}=3.00$; $\mathrm{U}=185.00, \mathrm{Z}=-4.07, \mathrm{p}<0.05)$. In phoneme isolation of final sounds, the treatment group scored significantly higher $(\mathrm{Mdn}=5.00)$ than did the comparison group (Mdn $=3.00 ; \mathrm{U}=163.50, \mathrm{Z}=-4.43, \mathrm{p}<0.05)$. As for phoneme blending, the difference was registered significant by the values of $U=184.50, Z=-4.09$, and $p<0.05$, with median scores of 5.00 for treatment group and 3.00 for the comparison group. For phoneme segmentation, the treatment group had a median value of 5.00 , while the comparison group obtained a median score of 2.00 . The difference was significant, with the values $U=171.00, Z=$ 4.25 , and $\mathrm{p}<.05$.

For phoneme deletion of initial sounds, the treatment group scored a higher median score $(\mathrm{Mdn}=5.00)$ than did the comparison group $(\mathrm{Mdn}=2.00)$, with the significant values of $U=177.50, Z=-4.16$, and $p<0.05$. Similar data were reported for phoneme deletion of final sounds task, in which the comparison group $(\mathrm{Mdn}=2.00)$ scored significantly lower than did the treatment group $(\mathrm{Mdn}=4.00 ; \mathrm{U}=186.50, \mathrm{Z}=-4.02, \mathrm{p}<0.05)$. As for phoneme deletion of the first sound in a blend, the treatment group had a median score of 4.00 , which was higher than that of the comparison group $(\mathrm{Mdn}=0.00)$. The difference value was found to be significant, at $\mathrm{U}=155.00, \mathrm{Z}=-4.48$, and $\mathrm{p}<0.05$. Finally, for phoneme substitution of initial and final sounds, the difference between the treatment $(\mathrm{Mdn}=4.00)$ and comparison groups $(\mathrm{Mdn}=0.00)$ were identified to be significant $(\mathrm{U}=176.50, \mathrm{Z}=-4.17, \mathrm{p}<.05)$, despite the similar value of median score.

Table 4. Results of Mann Whitney $U$ test for specific skills during the time of posttest.

\begin{tabular}{|c|c|c|c|c|c|c|c|}
\hline Skills & Groups & $\mathrm{N}$ & Median & Mean Rank & Mann-Whitney U & $\mathrm{Z}$ & Sig. \\
\hline \multirow{2}{*}{ Syllable Blending } & Comparison & 30 & 4.00 & 18.80 & \multirow{2}{*}{99.00} & \multirow{2}{*}{-5.50} & \multirow{2}{*}{.00} \\
\hline & Treatment & 30 & 5.00 & 42.20 & & & \\
\hline \multirow{2}{*}{ Syllable Segmentation } & Comparison & 30 & 3.00 & 24.17 & \multirow{2}{*}{260.00} & \multirow{2}{*}{-2.99} & \multirow{2}{*}{.00} \\
\hline & Treatment & 30 & 5.00 & 36.83 & & & \\
\hline \multirow{2}{*}{ Syllable Deletion } & Comparison & 30 & 3.00 & 26.97 & \multirow{2}{*}{330.00} & \multirow{2}{*}{-2.07} & \multirow{2}{*}{.03} \\
\hline & Treatment & 30 & 4.00 & 34.03 & & & \\
\hline \multirow{2}{*}{ Rhyme Recognition } & Comparison & 30 & 4.00 & 21.57 & \multirow{2}{*}{182.00} & \multirow{2}{*}{-4.32} & \multirow{2}{*}{.00} \\
\hline & Treatment & 30 & 5.00 & 39.43 & & & \\
\hline \multirow{2}{*}{ Onset-rime Production } & Comparison & 30 & 3.00 & 21.72 & \multirow{2}{*}{186.50} & \multirow{2}{*}{-4.07} & \multirow{2}{*}{.00} \\
\hline & Treatment & 30 & 5.00 & 39.28 & & & \\
\hline \multirow{2}{*}{$\begin{array}{l}\text { Phoneme Isolation of Initial } \\
\text { Sounds }\end{array}$} & Comparison & 30 & 3.00 & 21.67 & \multirow{2}{*}{185.00} & \multirow{2}{*}{-4.07} & \multirow{2}{*}{.00} \\
\hline & Treatment & 30 & 5.00 & 39.33 & & & \\
\hline \multirow{2}{*}{$\begin{array}{l}\text { Phoneme Isolation of Final } \\
\text { Sounds }\end{array}$} & Comparison & 30 & 3.00 & 20.95 & \multirow{2}{*}{163.50} & \multirow{2}{*}{-4.43} & \multirow{2}{*}{.00} \\
\hline & Treatment & 30 & 5.00 & 40.05 & & & \\
\hline \multirow{2}{*}{ Phoneme Blending } & Comparison & 30 & 3.00 & 21.65 & \multirow{2}{*}{184.50} & \multirow{2}{*}{-4.09} & \multirow{2}{*}{.00} \\
\hline & Treatment & 30 & 5.00 & 39.35 & & & \\
\hline Phoneme Seomentation & Comparison & 30 & 2.00 & 21.20 & 17100 & 425 & 00 \\
\hline P noneme segmentation & Treatment & 30 & 5.00 & 39.80 & 171.00 & -4.25 & .00 \\
\hline Phoneme Deletion of Initial & Comparison & 30 & 2.00 & 21.42 & 17750 & 416 & 00 \\
\hline Sounds & Treatment & 30 & 5.00 & 39.58 & $17 / .00$ & -4.10 & .00 \\
\hline Phoneme Deletion of Final & Comparison & 30 & 2.00 & 21.72 & 18650 & 402 & 00 \\
\hline Sounds & Treatment & 30 & 4.00 & 39.28 & 100.30 & -4.02 & .00 \\
\hline Phoneme Deletion of First Sound & Comparison & 30 & .00 & 20.67 & 15500 & 448 & 00 \\
\hline in Blend & Treatment & 30 & 4.00 & 40.33 & 150.00 & -4.40 & .00 \\
\hline Phoneme Substitution - Initial and & Comparison & 30 & .00 & 21.38 & 17650 & 417 & 00 \\
\hline Final Sounds & Treatment & 30 & 4.00 & 39.62 & $1 / 6.50$ & -4.17 & .00 \\
\hline
\end{tabular}


Table 5. Results of paired samples t-test from treatment group

\begin{tabular}{|c|c|c|c|c|c|c|c|}
\hline & & $\mathrm{N}$ & Mean & Std. Dev. & $\mathrm{t}$-Value & Sig. & $\begin{array}{c}\text { Effect size, Cohen's } \\
d\end{array}$ \\
\hline \multirow{2}{*}{ Syllable Awareness } & Pre-test & 30 & 41.67 & 20.10 & \multirow{2}{*}{14.99} & \multirow{2}{*}{.000} & \multirow{2}{*}{2.74} \\
\hline & Post-test & 30 & 81.67 & 12.56 & & & \\
\hline \multirow{2}{*}{$\begin{array}{l}\text { Onset-Rime } \\
\text { Awareness }\end{array}$} & Pre-test & 30 & 40.83 & 12.45 & \multirow{2}{*}{12.07} & \multirow{2}{*}{.000} & \multirow{2}{*}{2.20} \\
\hline & Post-test & 30 & 77.78 & 18.22 & & & \\
\hline \multirow{2}{*}{$\begin{array}{l}\text { Phonemic } \\
\text { Awareness }\end{array}$} & Pre-test & 30 & 34.93 & 14.53 & \multirow{2}{*}{14.01} & \multirow{2}{*}{.000} & \multirow{2}{*}{2.56} \\
\hline & Post-test & 30 & 71.04 & 20.80 & & & \\
\hline
\end{tabular}

\subsection{Research Question 2}

A paired-samples t-test was performed to observe whether the differences of performance during pre- and posttests were significant. Based on the research question, null and alternative hypotheses derived in accordance with the question were as follows.

$\mathrm{H}_{0}$ : No significant difference in pupils' PA was observed in the treatment group before and after the intervention's implementation.

$\mathrm{H}_{\mathrm{a}}$ : A significant difference in pupils' PA was observed in the treatment group before and after the intervention's implementation.

Before the paired t-test was run, the normality test was performed on the treatment group's data. Based on results of the Shapiro-Wilk normality test, at $\mathrm{n}=30$ and $\mathrm{p}>0.05$, the data were normally distributed. The effect sizes of the interventions were calculated using Cohen's $d$ formula as mentioned in the last chapter. Results from the test were as follows. (Table 5)

A paired-samples t-test was performed to compare the PA performances during the pre and posttests for the treatment group. A significant difference was observed in syllable awareness for posttest $(\mathrm{M}=81.67, \mathrm{SD}=12.56)$, and pre-test $(\mathrm{M}=41.67, \mathrm{SD}=20.10) ;(\mathrm{t}(29)=14.99, \mathrm{p}=$ $0.00)$. The magnitude of the differences in the means was very high $(\mathrm{d}=2.74)$. As for onset-rime awareness, significant difference was observed in pupils' performances in pre-test $(\mathrm{M}=40.83, \mathrm{SD}=12.45)$, in comparison with posttest $(\mathrm{M}=77.78, \quad \mathrm{SD}=18.22) ; \quad(\mathrm{t}$ $(29)=12.07, p=.00)$. The effect size that explained the magnitude of means' differences was very large $(d=2.20)$. Finally, for phonemic awareness, a similar situation was observed. A significant difference was observed when a comparison was made between pre-test $(\mathrm{M}=34.93, \mathrm{SD}=$ $14.53)$ and posttest $(\mathrm{M}=71.04, \mathrm{SD}=20.80)$; ( $\mathrm{t}(29)=14.01$, $\mathrm{p}=.00$ ), with the value of effect size 2.56 . These three values of effect sizes indicated a very strong relationship between the intervention and pupils' performances. The null hypothesis was rejected in favor of the alternative hypothesis.

\section{Discussion and Conclusions}

The present study explored the effects and benefits of multisensory learning approach on young ESL learners' PA development in a rural setting. Data obtained showed that a huge number of Year 1 pupils had a profound understanding and mastery of PA on syllable and onset-rime levels. Most samples demonstrated a high understanding of initial phoneme detection. These findings are consistent with previous studies by Bandini et al. [14] and Duranovic et al. [25], which proved the hierarchical development of PA. Based on the elaborated data in the previous section, samples in both treatment and comparison groups improved in PA. Although the pretest measures revealed that the differences in PA during the period existed, statistical analysis showed that the differences were insignificant. However, the treatment group demonstrated larger improvements in PA during the posttest period, compared with the control group. Results from the Mann Whitney U statistically suggested that the differences found in syllable, onset-rime, and phonemic awareness were significant during posttest. The stronger and rapid gains in PA acquisition on all PA tiers in treatment group could be attributed to the interventions received. Results from the paired sample t-test postulated and conclusively proved that the differences obtained from posttest and pretest in the treatment group were highly significant. Effect sizes were calculated using Cohen's $d$ formula, and the results acknowledged that the effect sizes between the two periods were very large, signifying that the interventions used benefited treatment students' PA development greatly and significantly.

Findings from the present study corroborated and were generally consistent with past studies that examined the application of multisensory inspired learning interventions $[3,5,19,34,35,39]$ to enhance PA development among young learners in ELL and ESL settings outside of Malaysian settings. Effect sizes ranging from moderate to large were presented in previous empirical studies, signifying the positive effects of multisensory learning on children's PA. In Malaysian settings, findings from this particular study were consistent with previous literature that used Jolly Phonics [20,43,44], OG Approach [24] and self-invented multisensory inspired interventions [8] in enhancing PA among young children in Malaysian rural localities. Findings from this study verified that the intervention did much to ameliorate children's PA. Thus, the use of a multisensory learning approach will 
significantly benefit and enhance the gains of PA among young learners and further accommodate their progress in reading the targeted language.

The findings from this study explained that the learning of L2 can be improved among rural dwellers [20]. Children's PA could be enhanced greatly through the appropriate use of pedagogical approaches that were carefully developed through multiple considerations in the aspects of applicability, scientific foundations, and creativity. The findings in a way opened some insights among English language teachers around Malaysia to emphasize the use of effective teaching strategies in the classroom setting, as well as the home-learning environment, especially when remote learning takes place in our education landscape. Data from this study in a way proved that rural ESL pupils are technologically ready and accepting towards computer-based instructions [33]. The data might be helpful in addressing reading problems that are likely to occur among Malaysian learners, namely, lacking of PA [36], and enhancing and strengthening the English language learning in Malaysia, regardless of geographical and demographical factors. The data obtained from the tests were considered greatly important in assisting teachers to come up with strategic schemata in to overcome early problems in reading because PA is fundamental to later reading $[4,30,31,40]$. The findings from this data were able to contribute to the empirical literature on PA progress among young ESL learners in Malaysia because PA is considered new to this setting [43].

This research had some limitations in the aspects of research design, which were highly related to the sample size. The research was only conducted in one school in the Maludam area that comprised three Year 1 classes. Teachers' methodologies in phonics instructions are well developed and perhaps limited only to certain phonological aspects. Some pupils here had undergone two years of preschool education, possibly greatly influencing their perceptions of PA, giving them an advantage in this matter. Another limiting factor was the environmental factors that were uncontrollable by the researcher, possibly influencing the results. Furthermore, children's family backgrounds could also affect the outcomes of this study, in which a more well-off family could afford a vast array of early learning opportunities compared with that of low-income families in terms of home-based education. As such, the generalization on a larger scale would be presumptuous or irrelevant at some points. Finally, the aspect of accessibility to instruments was one of the limiting factors in this study. The tests used were cost-effective, and some PA tests are cost-prohibitive. Furthermore, this study was the first time that this type of instrument was accessed in this setting. Thus, the results might be different depending on the settings.

In conclusion, the findings of this study clarified that the multisensory learning approach is able to yield positive outcomes in improving PA among young ESL learners. The findings proved that most learners at the age of 7 have a profound understanding and sensitivity of oral knowledge at syllable and onset-rime levels. Thus, PA develops over time as children grow older and become more aware of oral sounds. The use of the multisensory learning approach through various modalities positively affected children's PA development. This study is hoped to benefit future researchers to form a perception of children's PA development in rural settings in Malaysia.

\section{Acknowledgements}

This study is supported by the Malaysian Ministry of Education Research Grant FRGS/1/2018/SS09/UKM/02/1

\section{REFERENCES}

[1] B. Gorjian, M. Alipour, R. Saffarian. The Effect of Multisensory Techniques on Reading Comprehension among Pre-Intermediate EFL Learners: The Case of Gender, Advances in Asian Social Science, Vol.1, No.2, 192-195, 2012.

[2] B. Philip, K.H. Tan, W. Jandar. Exploring Teacher Cognition in Malaysian ESL Classrooms. 3L: Language, Linguistics, Literature ${ }^{\circledR}$, Vol.25, No.4. 156-178, 2019.

[3] B. S. Y. Mak, A. C. K. Cheung, X. Guo, P. C. Abrami, A. Wade. Examining the impact of the ABRACADABRA (ABRA) web-based literacy program on primary school students in Hong Kong, Education Information Technology, Vol.22, 2671-2691, 2017.

[4] C. Wilsenach, P. Makaure. Gender effects on phonological processing and reading development in Northern Sotho children learning to read in English: A case study of Grade 3 learners, South African Journal of Childhood Education, Vol.8, No.1, 2018.

[5] D. Messer, G. Nash. An evaluation of the effectiveness of a computer-assisted reading intervention, Journal of Research in Reading, Vol.41, No.1, 140-158, 2018.

[6] D. Wasserstein, O. Lipka. Predictive Examination of Phonological Awareness Among Hebrew-Speaking Kindergarten Children, Frontiers in Psychology, Vol.10, 2019.

[7] E. D. B. Tajuddin, P.B.M. Shah. Teachers' Knowledge of Phonemic Awareness and Its Instruction in ESL Learning Sub-Urban Primary School in Malaysia, International Journal of Technical Research and Applications, Special Issue 22, July 2015, 72-79, 2015.

[8] F. Gon, M. M. Yunus. The Use of Interactive Digital Phonics Show (IDPS) to Enhance PA among Young Learners, International Journal of Innovative Research and Creative Technology, Vol.5, No.1, 1-8, 2019. 
[9] G. Ursachi, A. Zait, I. A. Horodnic. How reliable are measurement scales? External factors with indirect influence on reliability estimators, 7th International Conference on Globalization and Higher Education in Economics and Business Administration, 679-686, 2013.

[10] G. Volpe, M. Gori. Multisensory Interactive Technologies for Primary Education: From Science to Technology, Frontiers in Psychology, Vol.10, 2019.

[11] G. T. Gillon. PA From Research to Practice. 2nd Edition, The Guilford Press, New York, 2018.

[12] H. White, S. Sabarwal. Quasi-experimental Design and Methods, Methodological Briefs: Impact. Evaluation 8, UNICEF Office of Research, Florence, 2014.

[13] H. Winskel. Learning to Read in Multilingual Malaysia: A Focus on Bahasa Melayu, Tamil and Chinese, GEMA Online ${ }^{\circledR}$ Journal of Language Studies, Vol.20, No.1, 2020.

[14] H. H. M. Bandini, F. H. Santos, D. D. G. D. Souza. Levels of PA, Working Memory, and Lexical Knowledge in Elementary School Children, Paidéia, Vol.23, No.56, 329-337, 2013.

[15] H. K. Yopp, R. H. Yopp. Purposeful Play for Early Childhood Phonological Awareness, Shell Education, California, 2013.

[16] I. Etikan, S. A. Musa, R. S. Alkassim. Comparison of Convenience Sampling and Purposive Sampling. American Journal of Theoretical and Applied Statistics, Vol5, No.1, 1-4, 2016.

[17] J. L. Anthony, D. J. Francis. Development of Phonological Awareness, American Psychological Society, Current Directions in Psychological Science, Vol.14, No.5, 255-259, 2005.

[18] J. R. Rains, C. A. Kelly, R. L. Durham. The Evolution of the Importance of Multi-Sensory Teaching Techniques in Elementary Mathematics: Theory and Practice, Journal of Theory and Practice in Education, Vol.4, No.2, 239-252, 2008 .

[19] J. R. Wolgemuth, R. Savage, J. Helmet, H. Harper, T. Lea, P. C. Abrami, A. Kirby, K. Chalkiti, P. Morris, J. Carapetis, W. Louden. ABRACADABRA aids Indigenous and non-Indigenous early literacy in Australia: Evidence from a multisite randomized controlled trial, Computers and Education, Vol.67, 250-264, 2013.

[20] K. A. Jamaludin, N. Alias, R. J. M. Khir, D. DeWitt, H. B. Kenayathula. The effectiveness of synthetic phonics in the development of early reading skills among struggling young ESL readers, School Effectiveness and School Improvement: An International Journal of Research, Policy and Practice, 3453, 1-16, 2015.

[21] K.H.Tan, A. Farashaiyan, R. Sahragard \& R. Faryabi. Implications of English as an International Language for Language Pedagogy. International Journal of Higher Education, Vol.9, No.1,2020.

[22] L. H. Ang \& K. H. Tan, He, M. Y. A Corpus-based Collocational Analysis of Noun Premodification Types in Academic Writing. 3L The Southeast Asian Journal of English Language Studies, Vol.23,No.1, 115-135,2017.

[23] L. J. Kuo, Y. Uchikoshi, T. J. Kim, X. Yang. Bilingualism and Phonological Awareness: Re-examining Theories of Cross-Language Transfer and Structural Sensitivity. Contemporary Education Psychology, July 2016, No.46, 19, 2016.

[24] L.W. Lee. Multisensory modalities for blending and segmenting among early readers, Computer Assisted Language Learning, Vol.29, No.5, 1-16, 2016.

[25] M. Duranovic, M. Huseinbasic, Tinjak, S. Development of Phonological Awareness and Letter Knowledge in Bosnian Preschool Children, International Journal of Linguistics, Vol.4, No.2, 18-34, 2012.

[26] M. Pfost. Children's Phonological Awareness as a Predictor of Reading and Spelling: A Systematic Review of Longitudinal Research in German-Speaking Countries, Zeitschrift für Entwicklungspsychologie und Pädagogische Psychologie, Vol.47, No.3, 123-138, 2015.

[27] M. Melby-Lervåg, S. H. Lyster, C. Hulme, Phonological Skills and Their Role in Learning to Read: A Meta-Analytic Review, Psychological Bulletin, Vol.138, No.2, 322-352, 2012.

[28] M. C. Law, K. F. Hew. Effect of Computer-Assisted Intervention on Early Phonological Processing Skills for Kindergarten Children in Hong Kong, International Journal of Information and Education Technology, Vol.7, No.12, 876-883, 2017.

[29] M. H. Alhumsi, A. A. Shabdin, A. A. The Relationship between Phonemic Segmentation Skill and EFL Word Recognition - A Review of Literature, International Journal of Linguistics, Vol. 8, No. 2, 31-46, 2016.

[30] M. L. Chapman. Phonemic Awareness: Clarifying What We Know, Literacy Teaching and Learning, Vol.7, No.2, 91-114, 2003.

[31] N. Chipere. Sex Differences in phonological awareness and reading ability, Language Awareness, Vol.23, No.3, 275-289, 2014.

[32] N. A. Piquette, R. S. Savage, P. C. Abrami. A cluster randomized control field trial of the ABRACADABRA web-based reading technology: replication and extension of basic findings, Frontiers in Psychology, No.5, 2014.

[33] N.I.M. Fuad, P.M. Shah \& M. Mohamad. ESL Pupils' Acceptance towards Web-based Speaking Skills Resource: Sub-urban and Rural Context. Universal Journal of Educational Research Vol.7, No.10A, 60-65, 2019.

[34] P. Macaruso, A. Rodman. Efficacy of Computer Assisted Instruction for the Development of Early Literacy Skills in Young Children, Reading Psychology, Vol.32, No.2, 172-196, 2011.

[35] P. O'Callaghan, A. McIvor, C. McVeigh, T. Rushe. A randomized controlled trial of an early intervention, computer-based literacy program to boost phonological skills in 4- to 6-year-old children, British Journal of Educational Psychology, Vol.86, No.4, 546-558, 2016.

[36] R. C. Johnson, M. G. Tweedie. Could Phonemic Awareness Instruction Be (Part of) the Answer for Young EFL Learners? A Report on the Early Literacy Project in Malaysia, TESOL Quarterly, 822-829, 2010.

[37] S. C. Korkmaz, C. Karatepe. The Impact of Multi-Sensory 
Language Teaching on Young English Learners' Achievement in Reading Skills, Novitas-ROYAL (Research on Youth and Language), Vol.12, No.2, 80 - 95, 2018.

[38] S. N. Aja, P. I. Eze, D. I. Igba, E. C. Igba, C. Nwafor, S. C. Nnamani. Using Multi-Sensory Instruction in Managing Classroom for Effective Teaching and Learning, International Journal of Applied Engineering Research, Vol.12, No.24, 15112 - 15118, 2017.

[39] S. S. Yeung, L. S. Siegel, C. K. K. Chan. Effects of a PA program on English reading and spelling among Hong Kong Chinese ESL children, Reading Writing Vol.26, 681-704, 2013.

[40] S. R. S. Moura, C. L. Mezzomo, C. A. Cielo. Phonemic Awareness stimulation and its effects regarding the variable gender, Pro-Fono Revista de Atualizacao Cientifica, Vol.21, No.1, 51-56, 2009.
[41] T. Sulaiman, Ayub, A. F. M., Sulaiman, S. Curriculum Change in English Language Curriculum Advocates Higher Order Thinking Skills and Standards-Based Assessments in Malaysian Primary Schools, Mediterranean Journal of Social Sciences, Vol.6, No.2, 494-500, 2015.

[42] Y. Peñaloza-López, A. Herrera-Rangel, S.J. Pérez-Ruiz, Poblano, A. Phonological awareness and sinusoidal amplitude modulation in phonological dyslexia, Arq Neuropsiquiatr, Vol.74, No.4,293-298, 2016.

[43] Y. A. Anthony, N. E. M. Said. The Effect of Synthetic Phonics on ESL Pupils' PA, International Journal of New Technology and Research (IJNTR), Vol.5, No.7, 92-97, 2019.

[44] Z. Ahmad, M. M. Yunus. The Effectiveness of Using Jolly Phonics Blending Phonemes to Year 3 English Language Classroom, International Journal of Humanities, Philosophy and Language, Vol.2, No.8, 150-162, 2019. 